Article

\title{
In Vitro and In Vivo Antioxidant Activity of a Water-Soluble Polysaccharide from Dendrobium denneanum
}

\author{
Aoxue Luo ${ }^{1, \dagger}$, Zhongfu Ge ${ }^{2}$, Yijun Fan ${ }^{1,+*}$, Aoshuang Luo ${ }^{3}$, Ze Chun ${ }^{3}$ and XingJin He ${ }^{4}$ \\ 1 Department of Landscape Plants, Chengdu Campus of Sichuan Agriculture University, Chengdu \\ 611130, China \\ 2 United States Geological Survey, Lake Michigan Ecological Research Station, Porter, IN 46304, \\ USA \\ 3 Chengdu Institute of Biology, Chinese Academy of Sciences, Chengdu 610041, China \\ 4 College of Life Sciences, Sichuan University, Chengdu 610064, China \\ $\dagger$ These authors contributed equally to this work.
}

* Author to whom correspondence should be addressed; E-Mail: Yijfan@yahoo.com.cn.

Received: 12 January 2011; in revised form: 9 February 2011 / Accepted: 11 February 2011 / Published: 14 February 2011

\begin{abstract}
The water-soluble crude polysaccharide (DDP) obtained from the aqueous extracts of the stem of Dendrobium denneanum through hot water extraction followed by ethanol precipitation, was found to have an average molecular weight $(\mathrm{Mw})$ of about $484.7 \mathrm{kDa}$. Monosaccharide analysis revealed that DDP was composed of arabinose, xylose, mannose, glucose and galactose in a molar ratio of 1.00:2.66:8.92:34.20:10.16. The investigation of antioxidant activity both in vitro and in vivo showed that DDP is a potential antioxidant.
\end{abstract}

Keywords: Dendrobium denneanum; polysaccharide; antioxidant activity

\section{Introduction}

Dendrobium denneanum (Orchidaceae) is a precious herbal plant highly valued in Traditional Chinese Medicine and archived in the Pharmacopoeia of the People's Republic of China. Sections of the stem from the Dendrobium species have been used for the treatment of salivary, ophthalmic 
disorders, fever and chronic superficial gastritis, or as a tonic for promoting the production of body fluids and for improving the quality of life [1]. As for Dendrobium species phytochemicals, much research has been carried out on the low molecular compounds, such as bibenzyl [2], phenanthrene [3], and alkaloids [4]. Based on previous studies, polysaccharides exist widely in numerous plants and are identified as essential biomacromolecules in plant life, playing important roles in cell-cell communication, cell adhesion, and molecular recognition in the immune system [5-8]. In recent years, some bioactive polysaccharides isolated from natural sources have attracted much attention in the field of biochemistry and pharmacology [9,10]. It has been proven that polysaccharides are major active constituents in Dendrobium species. Polysaccharides from some Dendrobium species, such as Dendrobium nobile Lindl [11,12], Dendrobium huoshanense [13] and Dendrobium chrysotoxum Lindl [14], have been isolated and reported to have beneficial effects on antioxidation, immunity stimulation and antitumor activities. However, the polysaccharides from Dendrobium denneanum have been little reported [15]. Therefore, the purpose of the present investigation was to elucidate the isolation and characterization of water-soluble polysaccharide from the stems of Dendrobium denneanum, as well as to evaluate its antioxidant activities in vitro and in vivo.

\section{Results and Discussion}

\subsection{Polysaccharide isolation and purification}

The total yield rate of crude polysaccharides was $15.3 \%$ by the boiling-water extraction method, followed by ethanol precipitation. Because of the presence of some colored materials and residual protein, DDP was a brown water-soluble powder. AB-8 and ADS-7 macroporous resin were used for further purification of the resulting DDP. After application of these two macroporous adsorption resins, protein eventually disappeared in the DDP and the polysaccharide DDP had gray-colored powder appearance. The total sugar content of the polysaccharide was estimated to be $99.7 \%$ by the phenol-sulfuric acid method. Previous research has indicated that the molecular weight of polysaccharide was an important factor responsible for biological activities [15]. Determining the molecular weight was therefore the first step for the study of the DDP polysaccharide. The molecular weight $\left(\mathrm{M}_{\mathrm{w}}\right)$ of DDP was calculated to be $484,700 \mathrm{Da}$ based on the calibration curve obtained with standard dextrans.

\subsection{Monosaccharide composition of DDP}

Monosaccharide composition of DDP was analyzed by the trifluoroacetic acid hydrolysis and GCMS analysis method. The results shown in Figure 1 indicate that glucose is a major monosaccharide constructing the backbones of DDP. DDP was found to be composed of arabinose, xylose, mannose, glucose, and galactose with a molar ratio of $1.00: 2.66: 8.92: 34.20: 10.16$. 
Figure 1. Monosaccharide composition of DDP by GC-MS analysis.

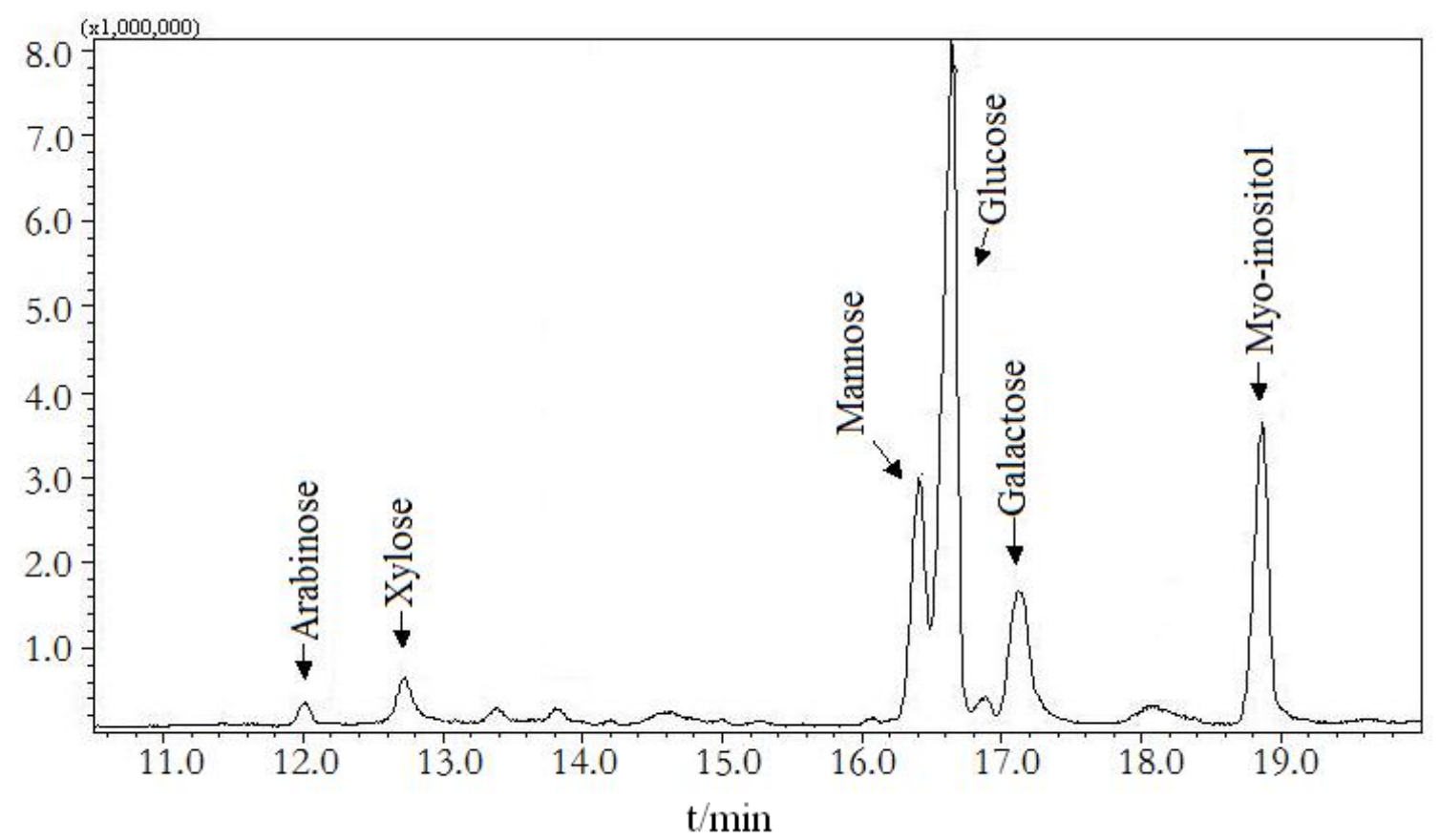

\subsection{Infrared spectra of $D D P$}

As shown in Figure 2, the sample of DDP exhibited a significant, broad characteristic peak at around 3,446 $\mathrm{cm}^{-1}$ for the hydroxyl group, as well as a weak $\mathrm{C}-\mathrm{H}$ band at around 2,927 $\mathrm{cm}^{-1}[16]$. The band at $1,638 \mathrm{~cm}^{-1}$ was due to the bound water [17]. The polysaccharide also appears to have a specific band between 1,200 and $1,000 \mathrm{~cm}^{-1}$, which is dominated by ring vibrations overlapped with stretching vibrations of $(\mathrm{C}-\mathrm{OH})$ side groups and the (C-O-C) glycosidic band vibration [18]. A characteristic peak at around $894 \mathrm{~cm}^{-1}$ was also found in DDP, indicating the $\beta$-configuration of the sugar units [19]. Positive specific rotation and characteristic absorption at around $869 \mathrm{~cm}^{-1}$ were identified in the IR spectrum, indicating the $\alpha$-configuration of the sugar units [20].

Figure 2. FT-IR spectra of the polysaccharide DDP.

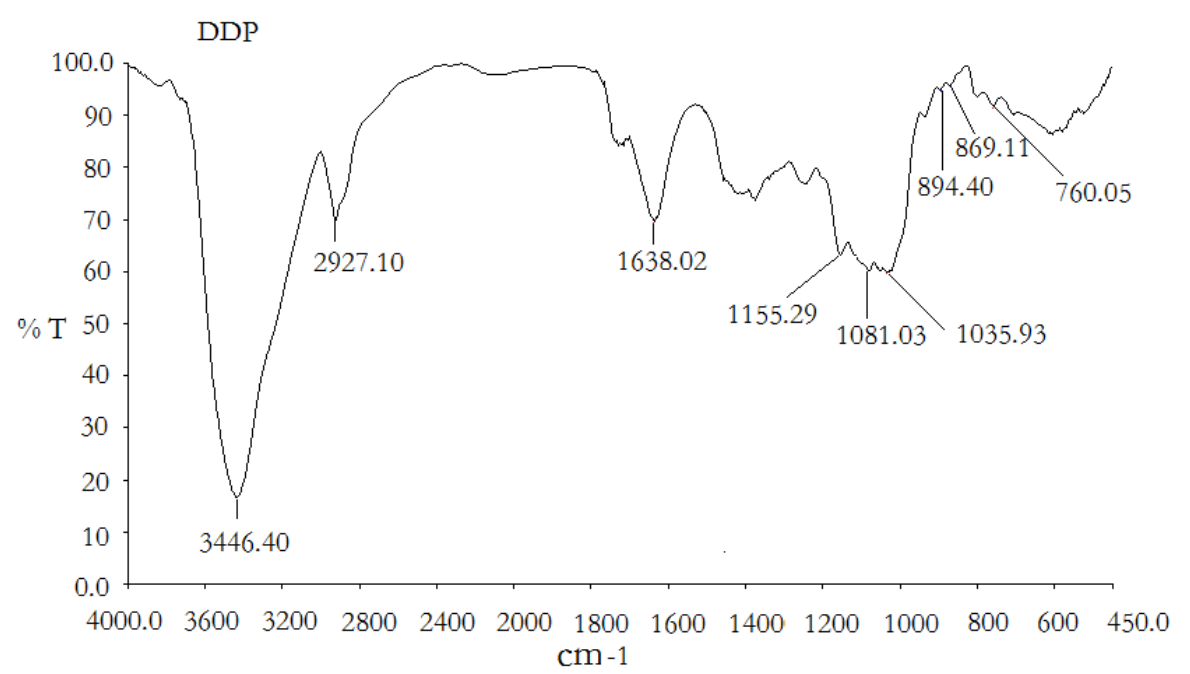




\subsection{NMR identification}

The ${ }^{1} \mathrm{H}-\mathrm{NMR}$ and ${ }^{13} \mathrm{C}-\mathrm{NMR}$ results for DDP are shown in Table 1 [21-24]. Based on the previous discussions in the literature, the signals were centered between $\delta 99.69$ and $102.57 \mathrm{ppm}$, indicating an $\alpha$ anomeric configuration for all monosaccharide residues of DDP (Figure 3A) [25,26]. The ${ }^{1} \mathrm{H}-\mathrm{NMR}$ spectrum of DDP showed two anomeric protons at 5.30 and 4.86 , which were assigned as $(1 \rightarrow 4)-\alpha-D-$ Glcp and (1 $\rightarrow 6)-\alpha-D-G l c p(L i$ et al. 2008), respectively (Figure 3B).

Table 1. ${ }^{1} \mathrm{H}$ NMR and ${ }^{13} \mathrm{C}$ NMR chemical shifts for DDP in $\mathrm{D}_{2} \mathrm{O}$ at $27{ }^{\circ} \mathrm{C}$.

\begin{tabular}{lllllll}
\hline Sugar residues & H-1 & H-2 & H-3 & H-4 & H-5 & H-6 \\
& C-1 & C-2 & C-3 & C-4 & C-5 & C-6 \\
\hline$\alpha$-D-Galp- $(1 \rightarrow$ & 5.12 & 3.84 & 3.87 & 4.01 & 4.08 & 3.70 \\
& 99.69 & 69.40 & 70.02 & 70.02 & 71.25 & 60.51 \\
$\alpha$-D-Manp- (1 $\rightarrow$ & 5.12 & 4.08 & 3.87 & 3.74 & 3.76 & 4.00 \\
& 102.57 & 70.02 & 71.25 & 69.40 & 73.37 & 60.51 \\
$\rightarrow 4,6)-\alpha$-D-Glcp- (1 $\rightarrow$ & 99.69 & 71.25 & 73.37 & 76.58 & 70.02 & 65.80 \\
& 4.86 & 3.54 & 3.70 & 3.56 & 4.01 & 3.66 \\
$\rightarrow 4)-\alpha$-D-Glcp- $(1 \rightarrow$ & 5.40 & 3.85 & 3.74 & 3.63 & 4.01 & 3.84 \\
& 102.57 & 73.37 & 76.58 & 78.00 & 76.86 & 62.50 \\
\hline
\end{tabular}

Figure 3. NMR analysis of DDP. A for ${ }^{13} \mathrm{C}-\mathrm{NMR}$ analysis of DDP, and $\mathrm{B}$ for ${ }^{1} \mathrm{H}-\mathrm{NMR}$ analysis of DDP.

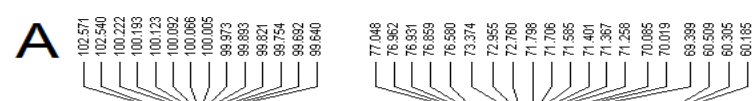

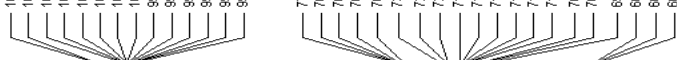
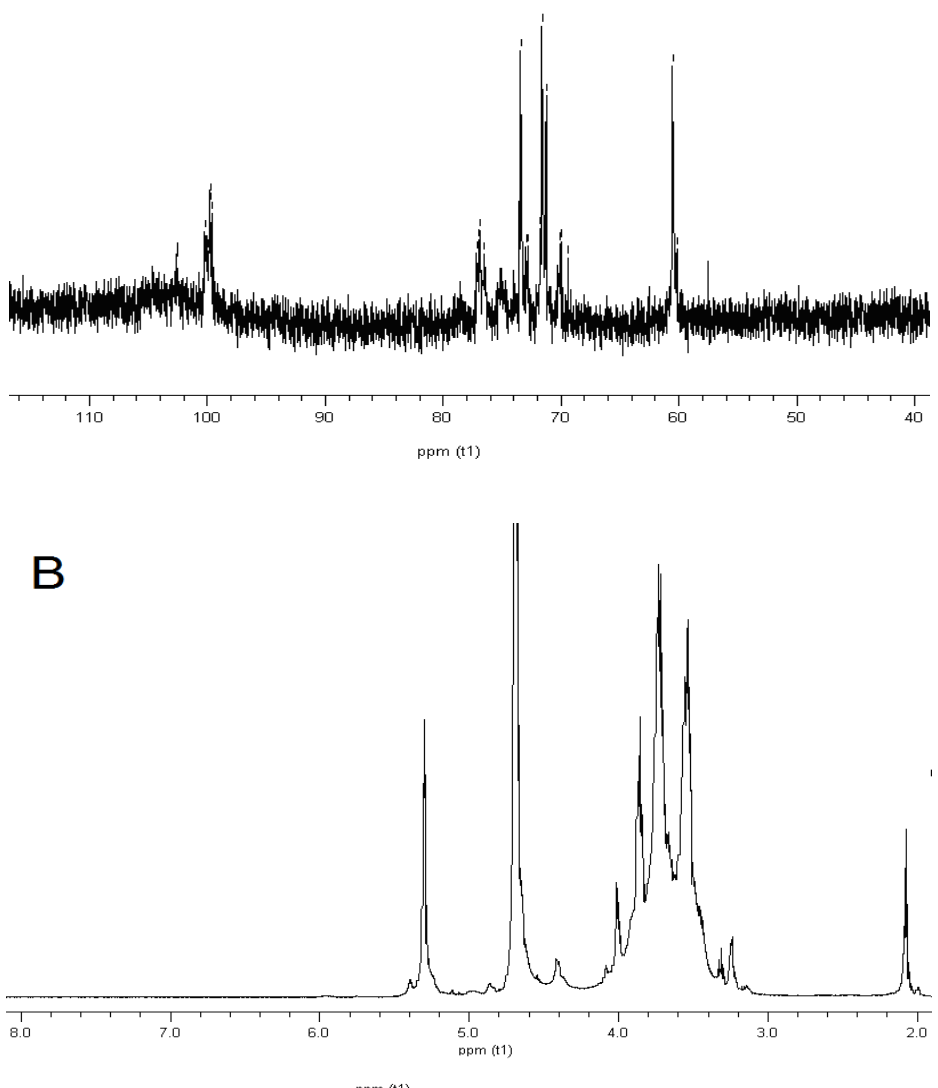


\subsection{Antioxidant activities analysis}

\subsubsection{Effect of scavenging DPPH radicals}

In this experiment, the scavenging ability of the purified polysaccharide DDP on DPPH free radical were examined in the concentration range of $10-2,000 \mu \mathrm{g} / \mathrm{mL}$ using the DPPH colorimetric assay (shown in Figure 4A).

Figure 4. Antioxidant activity of DDP in vitro. A: The scavenging effect of DDP on DPPH radical; B: The scavenging effect of DDP on hydroxyl radical; $\mathrm{C}$ : The scavenging effect of DDP on ABTS radical. Results are presented as means \pm standard deviations.
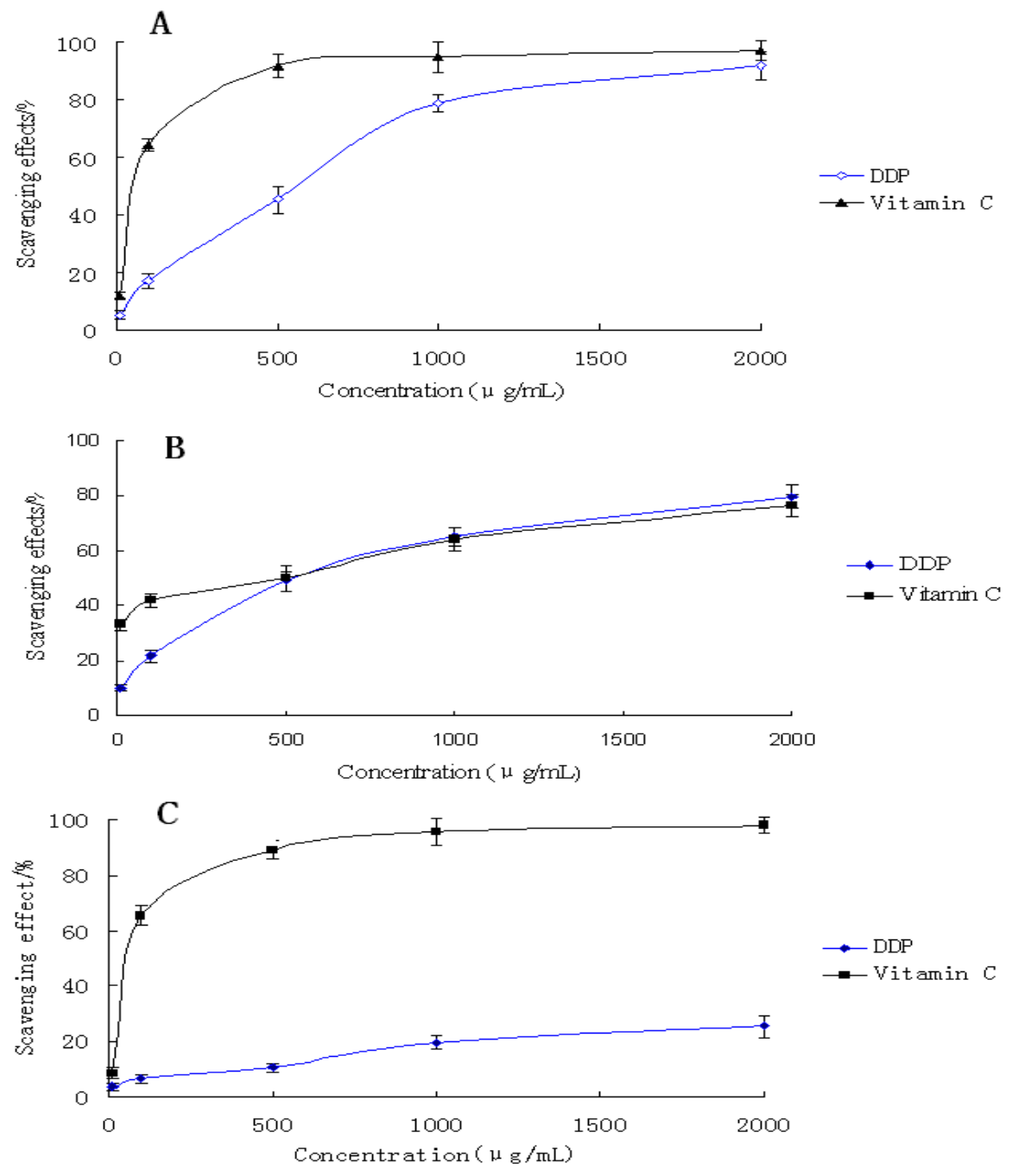

The results indicated that the activities of both samples increased in a concentration dependent manner. Furthermore, the scavenging activities of DDP increased very significantly with increasing concentrations. Especially at the high dose $(2,000 \mu \mathrm{g} / \mathrm{mL})$, DDP exhibited very high radical scavenging activity $(92.06 \%)$, which was close to that of vitamin $\mathrm{C}(\mathrm{p}<0.05)$. However, in the low doses (10 to $1,000 \mu \mathrm{g} / \mathrm{mL}$ ), the radical scavenging activity of DDP was lower than that of vitamin C. Therefore, it is obvious that the polysaccharide DDP has strong antioxidant activity in the high doses. 


\subsubsection{Scavenging effects of polysaccharide on hydroxyl radicals}

The results of hydroxyl radical scavenging activities of DDP compared to those of vitamin $\mathrm{C}$ are shown in Figure 4B. The samples exhibited obvious hydroxyl radical scavenging activities in a concentration-dependent manner. The polysaccharide was found to have the ability to scavenge hydroxyl radicals at concentrations between 500 and 2,000 $\mu \mathrm{g} / \mathrm{mL}$. At $500 \mu \mathrm{g} / \mathrm{mL}$, DDP revealed an excellent hydroxyl radical scavenging activity (48.9\%), similar to that of vitamin $\mathrm{C}(50.1 \%)$. At the high dose of 2,000 $\mu \mathrm{g} / \mathrm{mL}$, DDP also exhibited strong activity (79.8\%), which was higher than that of vitamin C. These results clearly showed that DDP has potential hydroxyl radical scavenging antioxidant ability.

\subsubsection{Scavenging effects of polysaccharide on ABTS}

The ABTS radical cation decoloration assay, which employs a specific absorbance (734 $\mathrm{nm})$ at a wavelength well separated from the visible-light range and requires only a short reaction time, has been widely applied to evaluating the total antioxidative activity in both lipophilic and hydrophilic samples [27]. The scavenging ability of DDP on ABTS free radical in the present experiments is shown in Figure 4C. The scavenging power of all samples correlated well with increasing concentrations. Moreover, vitamin $\mathrm{C}$ exhibited evident scavenging effect especially at high doses (from 500 to $2,000 \mu \mathrm{g} / \mathrm{mL}$ ). At $2,000 \mu \mathrm{g} / \mathrm{mL}$, the scavenging ability was $98.16 \%$. In contrast, the sample DDP revealed insufficient scavenging power against ABTS radical. Even at a high concentration of $2,000 \mu \mathrm{g} / \mathrm{mL}$, its scavenging ability was only $25.56 \%$, which was far lower than that of the control. Therefore, the results indicated that the polysaccharide DDP has no significant effect on ABTS radical scavenging.

\subsection{Antioxidant activity in vivo}

Superoxide dismutase (SOD) activity (U/mL) was tested with the SOD Assay Kit. Superoxide was generated in xanthine oxidase and hypoxanthine, and the superoxide scavenging effect of serum was determined according to the method of Oyanagui [28]. SOD activity of the serum was expressed in $\mathrm{U} / \mathrm{mL}$ of the sample. As shown in Figure 5A, SOD activities of different dose of DDP exhibited dosedependent manner. At $200 \mathrm{mg} / \mathrm{kg}$, particularly, SOD activity of DDP was $132.79 \mathrm{U} / \mathrm{mL}$, which was close to that of vitamin C. However, SOD activity at low concentrations was much less evident, which is similar to that of the negative control. The results were therefore an indication of enhancement SOD activity of DDP for high concentrations.

The concentrations of MDA in blood serum from the mice were determined with an MDA Assay Kit. The MDA value was estimated according to the thiobarbituric acid (TBA) method [29]. The samples added with TBA were heated in an acidic environment. The absorbance of the resulting solution was measured at $532 \mathrm{~nm}$. The results in Figure 5B exhibit a significant pattern of a decreasing MDA concentration in blood serum with increasing DDP concentration. At $200 \mathrm{mg} / \mathrm{kg}$, the concentration of MDA was $5.95 \mathrm{nmol} / \mathrm{mL}$, close to that of the positive control. This can be interpreted as a significant effect of DDP at high concentrations on MDA scavenging in vivo. 
Figure 5. Antioxidant activity of DDP in vivo. A: SOD activity analysis in mice; B: Determination of MDA contents in blood serum from the mice. Results are presented as means \pm standard deviations.
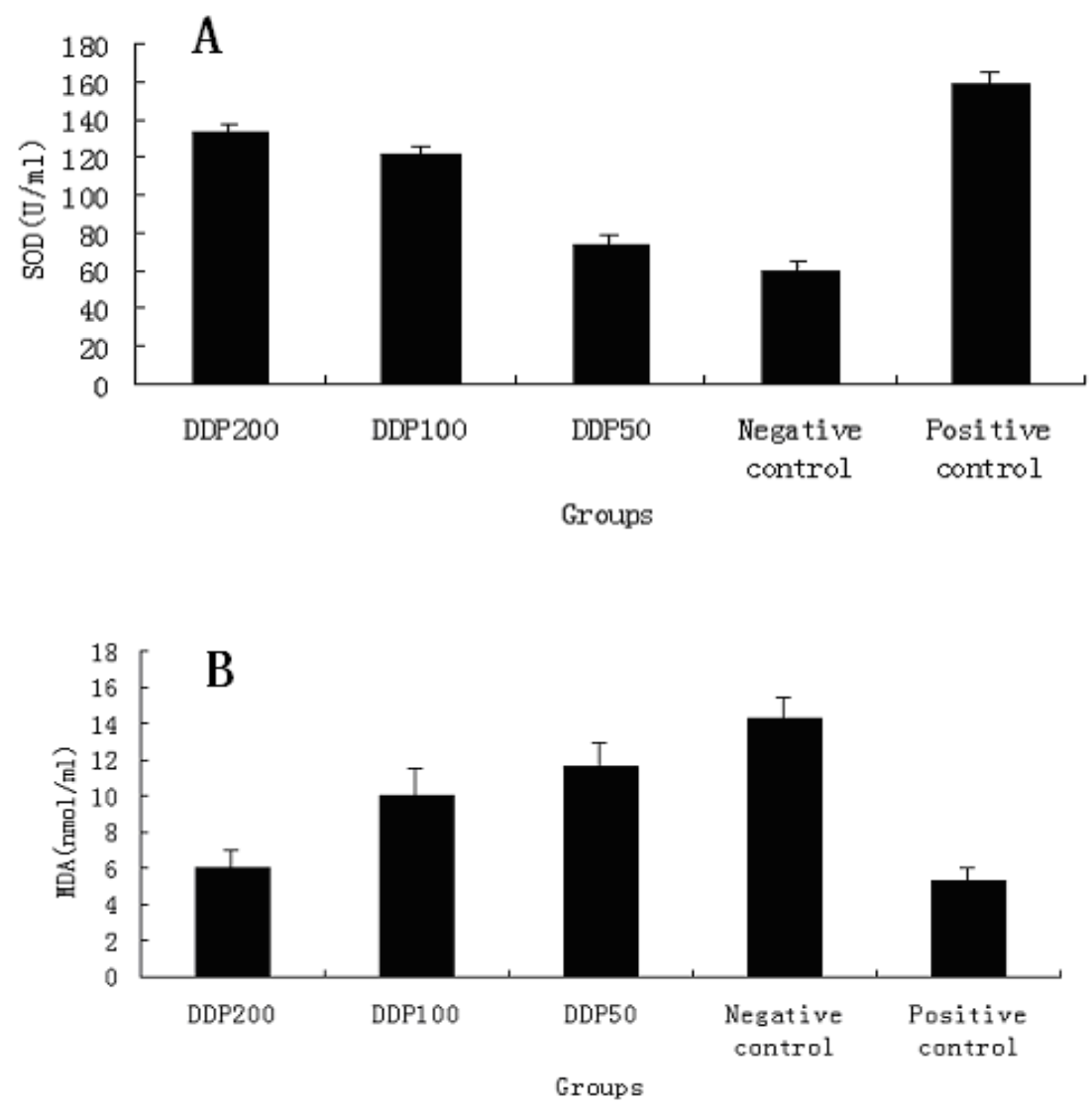

\section{Experimental}

\subsection{Materials and chemicals}

DPPH (1,1-diphenyl-2-picrylhydrazyl) radical and Vitamin C were purchased from Sigma (St. Louis, MO, USA). Dextrans of different molecular weights were purchased from Pharmacia Co. (Uppsala, Sweden). The standard monosaccharides (glucose, mannose, rhamnose, galactose, xylose and arabinose) were purchased from the Chinese Institute for the Control of Pharmaceutical and Biological Products (Beijing, China). ABTS (2,2-azinobis-6-(3-ethylbenzothiazoline sulfonic acid) radical was purchased from Merck (Darmstadt, Germany). AB-8 and ADS-7 were purchased from the Chemical Plant of Nankai University (Tianjin, China). SOD Assay Kit001 and MDA Assay Kit A003 were purchased from the Institute of Biological Engineering of Nanjing Jianchen (Nanjing, China). Trifluoroacetic acid (TFA), pyridine, methanol, and acetic acid, ethanol, acetic anhydride and all other chemicals and reagents were analytical grade.

\subsection{Extraction the crude polysaccharide from Dendrobium denneanum}

The stems of Dendrobium denneanum were thoroughly washed with water, dried at $60{ }^{\circ} \mathrm{C}$, and then powdered with a pulverizer. The powder was extracted with petroleum ether at $70{ }^{\circ} \mathrm{C}$ for $2 \mathrm{~h}$ to remove 
lipids. After filtered, the residues were air-dried, refluxed again with $80 \%$ ethanol at $90{ }^{\circ} \mathrm{C}$ for $2 \mathrm{~h}$, and then extracted with double-distilled water at $100{ }^{\circ} \mathrm{C}$ for $2 \mathrm{~h}$ thrice, filtered. The combined filtrate was precipitated with ethanol (4 times the volume of aqueous extract) at $4{ }^{\circ} \mathrm{C}$ for $24 \mathrm{~h}$. After filtration and centrifugation, the precipitate was dissolved in double-distilled water and deproteinized five times with the Sevag reagent [30]. It was subsequently dialyzed against deionized water for $72 \mathrm{~h}$ and lyophilized, which finally yielded the desired crude Dendrobium denneanum polysaccharides (DDP).

\subsection{Purification of polysaccharide}

Two macroporous adsorption resins, AB-8 and ADS-7, were used for purifying the crude polysaccharides of Dendrobium denneanum. AB-8 was selected for the decoloration of the DDP. The method was described by Xia et al. [31]. ADS-7 was used to remove the residuary protein according to the methods of Li et al. [32]. The crude polysaccharides were first dissolved in double-distilled water. After membrane filtration $(0.45 \mu \mathrm{m}$, Nucleopore $)$, the filtrate was injected to column $(26 \times 300 \mathrm{~mm})$ of AB-8 and ADS-7, respectively. The columns were eluted with distilled water. The carbohydrate contents of the samples were determined by the phenol-sulfuric acid method using glucose as standard [33]. Protein content was determined according to the method of Bradford et al. [34], with bovine serum albumin as standard.

\subsection{Determination of molecular weight}

The molecular weight of DDP was determined by the Gel Permeation Chromatography (GPC) technique as described by Yamamoto et al. [35] using a Waters HPLC apparatus (Waters 515, Waters Co. Ltd., USA) equipped with an Ultrahydrogel Linear Column $(300 \times 7.8 \mathrm{~mm})$ and a model 2410 Refractive index detector (RID). The column was eluted with $0.2 \mathrm{M}$ phosphate buffer (PH 7.0) with a flow rate of $0.7 \mathrm{~mL} / \mathrm{min}$ and calibrated with Dextran standards (molecular weights: 2,500, 4,600, $7,100,10,000,21,400,41,100,84,400,133,800,200,000 \mathrm{Da})$.

\subsection{Analysis of monosaccharide compositions}

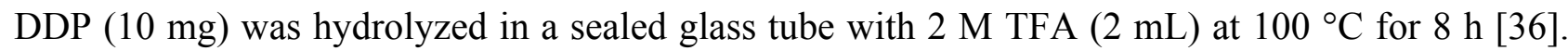
The hydrolysate was dried at a reduced pressure in preparation for acetylation. The acetylation was carried out using hydroxylamine hydrochloride $(10 \mathrm{mg})$ and pyridine $(0.5 \mathrm{~mL})$ heated in a water bath at $90{ }^{\circ} \mathrm{C}$ for $30 \mathrm{~min}$. The tube was afterwards cooled to room temperature before acetic anhydride $(0.5 \mathrm{~mL})$ was added and mixed thoroughly by vortexing. The tube was sealed and incubated in a water bath shaker at $90{ }^{\circ} \mathrm{C}$ for $30 \mathrm{~min}$. following a cooling process, an aliquot of the acetylation product $(3 \mu \mathrm{L})$ was loaded onto an Rtx-5SilMS column $(30 \mathrm{~m} \times 0.32 \mathrm{~mm} \times 0.25 \mu \mathrm{m})$ of a GC-MS (QP2010, Shimadzu, Japan). This step was carried out under the following conditions: injection temperature: $240{ }^{\circ} \mathrm{C}$; detector temperature: $240{ }^{\circ} \mathrm{C}$; column temperature programmed: $160{ }^{\circ} \mathrm{C}$ held for 2 min, increased to $240{ }^{\circ} \mathrm{C}$ at a rate of $5{ }^{\circ} \mathrm{C} / \mathrm{min}$ and finally maintained at $240{ }^{\circ} \mathrm{C}$ for $5 \mathrm{~min}$. Nitrogen was used as the carrier gas with a flow rate $1.0 \mathrm{~mL} / \mathrm{min}$. 


\subsection{Infrared spectra of DDP}

The purified polysaccharide was ground with $\mathrm{KBr}$ powder and then pressed into pellets for the estimation of the infrared (IR) spectra of DDP in the 4,000-500 $\mathrm{cm}^{-1}$ frequency range. Spectra were recorded on a Perkin-Elmer Fourier Transform IR spectrophotometer (Perkin-Elmer Corp., USA) [37].

\subsection{NMR Identification}

Twenty milligrams of DDP was dissolved in $\mathrm{D}_{2} \mathrm{O}(0.5 \mathrm{~mL}, 99.9 \%)$, freeze-dried, and redissolved in $\mathrm{D}_{2} \mathrm{O}(0.5 \mathrm{~mL})$. The ${ }^{1} \mathrm{H}-\mathrm{NMR}$ and ${ }^{13} \mathrm{C}$-NMR spectra were measured in an NMR tube (5-mm diameter) at $27^{\circ} \mathrm{C}$ with a Bruker Avance 600 spectrometer. The chemical shift was expressed in parts per million (ppm).

\subsection{Assays for antioxidant activities}

\subsubsection{DPPH radicals scavenging assay}

DPPH radical is a stable free radical that shows a maximum absorption at $517 \mathrm{~nm}$, and is widely used to evaluate the free radical scavenging ability of natural compounds. In the DPPH assay, the antioxidants were able to reduce the stable radical DPPH to the yellow coloured diphenylpicrylhydrazine. Therefore, the antioxidant activities of a sample can be expressed as its ability in scavenging the DPPH radical. In this study, the antioxidant activities were determined by the DPPH scavenging activities of the purified polysaccharides as described by Shimada et al. [38] with some modifications. Vitamin $\mathrm{C}$ was used as reference material. Briefly, 0.1-mM solution of DPPH in methanol was prepared, $1.0 \mathrm{~mL}$ of which was then mixed with purified polysaccharide solutions $(3.0 \mathrm{~mL})$ of various concentrations $(10-2,000 \mu \mathrm{g} / \mathrm{mL})$. The solution was kept at room temperature for $30 \mathrm{~min}$ before the absorbance at $517 \mathrm{~nm}\left(\mathrm{~A}_{517}\right)$ was measured. The DPPH scavenging effect was calculated as follows: DPPH scavenging effect $(\%)=\left[\mathrm{A}_{0}-\left(\mathrm{A}-\mathrm{A}_{\mathrm{b}}\right)\right] / \mathrm{A}_{0} \times 100\left(\mathrm{~A}_{0}\right.$ : the $\mathrm{A}_{517}$ of DPPH without the sample; $A$ : the $A_{517}$ of the sample and DPPH; $A_{b}$ : the $A_{517}$ of the sample without DPPH).

\subsubsection{Hydroxyl radical scavenging assay}

The antioxidant activity was determined by the scavenging effect of hydroxyl radical as described by Smirnoff and Cumbes [39], with some modifications. Briefly, vitamin $\mathrm{C}$ was used as reference material. DDP samples of different concentrations $(10-2,000 \mu \mathrm{g} / \mathrm{mL})$ were incubated with $2 \mathrm{mM}$ EDTA-Fe $(0.5 \mathrm{~mL}), 3 \% \mathrm{H}_{2} \mathrm{O}_{2}(1 \mathrm{~mL})$, and $360 \mu \mathrm{g} / \mathrm{mL}$ crocus in a $4.5-\mathrm{mL}$ sodium phosphate buffer $(150 \mathrm{mM}, \mathrm{pH} 7.4)$ at $37^{\circ} \mathrm{C}$ for $30 \mathrm{~min}$. Hydroxyl radical was detected by monitoring the absorbance at $520 \mathrm{~nm}$. The hydroxyl radical scavenging effect $(\%)$ was calculated as $\left[\left(A_{C}-A_{S}\right) / A_{C}\right] \times 100$, where $A_{S}$ and $A_{C}$ are the $A_{520}$ of the samples and the control group, respectively. The control group used distilled water and a sodium phosphate buffer in place of $\mathrm{H}_{2} \mathrm{O}_{2}$.

\subsubsection{ABTS radicals scavenging assay}

The ABTS radical cation scavenging activity of DDP was identified using the method given by Re et al. [40] with some modifications. ABTS was produced from the reaction of $7 \mathrm{mM}$ of ABTS 
solution with $2.45 \mathrm{mM}$ of potassium persulphate. The mixture was then kept in the dark at room temperature for $16 \mathrm{~h}$. At the time of use, the ABTS solution was diluted with ethanol to yield an absorbance of $0.70 \pm 0.02$ at $734 \mathrm{~nm}$. Samples $(0.2 \mathrm{~mL})$ of various concentrations $(10-2,000 \mu \mathrm{g} / \mathrm{mL})$ were mixed with ABTS solutions $(2 \mathrm{~mL})$. After reaction at room temperature for $6 \mathrm{~min}$, the absorbance at $734 \mathrm{~nm}$ was recorded. The ABTS scavenging effect was calculated based on the following formula: ABTS scavenging effect $(\%)=\left[\mathrm{A}_{0}-(\mathrm{As}-\mathrm{Ab})\right] / \mathrm{A}_{0} \times 100$, where $\mathrm{A}_{0}, \mathrm{As}$, and $\mathrm{A}_{\mathrm{b}}$ are the $\mathrm{A}_{734}$ of the ABTS without the sample, of the sample and ABTS, and of the sample without ABTS, respectively.

\subsubsection{Antioxidant activity in vivo}

Kunming mice (eight weeks old of age, $20 \pm 2 \mathrm{~g}$ of weight) were provided by Sichuan Academy of Medical Science, China. The mice were kept in separated cages at a temperature of $21 \pm 1{ }^{\circ} \mathrm{C}$ and a $50-60 \%$ of relative humidity. They underwent 12-h light-and-dark cycles with free access to food and water. A total of 50 mice were evenly and randomly divided into five groups, including a D-galactose model control group (negative control), a vitamin C (100 mg/kg) group (positive control), and dosedependent DDP groups (200, 100, and $50 \mathrm{mg} / \mathrm{kg}$ body weight). Each group was induced by a single intraperitoneal injection of D-galactose $(100 \mathrm{mg} / \mathrm{kg} /$ day body weight, dissolved in a $0.9 \%$ saline solution) [41]. The mice in the D-galactose model control group were given a $0.2-\mathrm{mL}$ physiological saline solution $(0.9 \% \mathrm{w} / \mathrm{v})$ once daily for 20 consecutive days by intraperitoneal injection. Twenty-four hours after the last drug administration, blood samples were obtained from the eyepit of the mice and processed for serum. The superoxide dismutase (SOD) activity and the malondialdehyde (MDA) level were also measured.

\subsection{Statistical analysis}

The data were presented as mean \pm standard deviation. Statistical analysis was conducted with the SPSS 16.0 software package.

\section{Conclusions}

Polysaccharides in many plants are not only energy resources but they play key biological roles in many life processes as well. The structure and mechanisms of pharmaceutical effects of bioactive polysaccharides on diseases have been extensively studied, and more natural polysaccharides with different curative effects have been tested and even applied in therapies [42]. Recent research has shown that some polysaccharides can play an important role as free radical scavengers for the prevention of oxidative damage in living organisms [43]. In the present study, the water-extracted polysaccharide from Dendrobium denneanum was purified with AB-8 and ADS-7 column chromatography, which yielded the polysaccharide DDP. In the subsequent antioxidant experiments in vitro, DDP exhibited strong scavenging ability on DPPH radical. The antioxidant effect of DDP is similar to that of vitamin $\mathrm{C}$. The damaging action of $\mathrm{OH}$ radical, which can react with all biological molecules such as proteins, lipids, and carbohydrates, is very strong [44] and the resulting oxidative stress can mediate a wide variety of degenerative processes and diseases $[45,46]$. In the assays above, the DDP polysaccharide exhibited very strong scavenging ability on hydroxyl radical. At the high dose 
of $2,000 \mu \mathrm{g} / \mathrm{mL}$, the antioxidant activity of DDP is higher than that of positive control (vitamin C). For in vivo assays, the DDP was found to increase the levels of antioxidant enzymes (SOD) and to decrease the MDA content in blood serum. It was confirmed that DDP could protect tissues against oxidative damages. Enhanced SOD activity in mice blood serum also can be related to the in vivo antioxidant activity of DDP. With such strong antioxidant ability, DDP was identified as a potential antioxidant.

\section{Acknowledgements}

This study was supported by the Education Department Foundation of Sichuan Province of China (08ZA074).

\section{References and Notes}

1. Yves, S.Y.H.; Cheng, C.; Sylvian, K.S.L.; Shih, F.L.; Wei, T.H.; Wen, B.Y.; Chih, C.L.; Ting, J.R.C.; Chia, C.C.; Jim, M.F.; Chi, H.W. Structure and bioactivity of the polysaccharides in medicinal plant Dendrobium huoshanense. Bioorg. Med. Chem. 2008, 16, 6054-6068.

2. Majumder, P.L.; Guha, S.; Sen, S. Bibenzyl derivatives from the orchid Dendrobium amoenum. Phytochemistry 1999, 52, 1365-1369.

3. Yang, L.; Qin, L.H.; Annie Bligh, S.W.; Bashall, A.; Zhang, C.F.; Zhang, M.; Wang, Z.T.; Xu, L.S. A new phenanthrene with a spirolactone from Dendrobium chrysanthum and its antiinflammatory activities. Bioorg. Med. Chem. 2006, 14, 3496-3501.

4. Wang, Q.; Gong, Q.; Wu, Q.; Shi, J. Neuroprotective effects of Dendrobium alkaloids on rat cortical neurons injured by oxygen-glucose deprivation and reperfusion. Phytomedicine 2010, 17, 108-115.

5. Tong, H.B.; Xia, F.G.; Feng, K.; Sun, G.R.; Gao, X.X.; Sun, L.W.; Jiang, R.; Tian, D.; Sun, X. Structural characterization and in vitro antitumor activity of a novel polysaccharide isolated from the fruiting bodies of Pleurotus ostreatus. Bioresource Technol. 2009, 100, 1682-1686.

6. Cao, W.; Li, X.Q.; Wang, X.; Fan, H.T.; Zhang, X.N.; Hou, Y.; Liu, S.B.; Mei, Q.B. A novel polysaccharide, isolated from Angelica sinensis (Oliv.) Diels induces the apoptosis of cervical cancer HeLa cells through an intrinsic apoptotic pathway. Phytomedicine 2010, 17, 598-600.

7. Kiyohara, H.; Matsumoto, T.; Yamada, H. Intestinal immune system modulating polysaccharides in a Japanese herbal (Kampo) medicine, Juzen-Taiho-To. Phytomedicine 2002, 9, 614-624.

8. Sun, Y.X.; Liang, H.T.; Zhang, X.T.; Tong, H.H.; Liu, J.C. Structural elucidation and immunological activity of a polysaccharide from the fruiting body of Armillaria mellea. Bioresource Technol. 2009, 100, 1860-1863.

9. Dwek, R.A. Glycobiology: Toward understanding the function of sugars. Chem. Rev. 1996, 96, 683-720.

10. Rout, S.; Banerjee, R. Free radical scavenging, anti-glycation and tyrosinase inhibition properties of a polysaccharide fraction isolated from the rind from Punica granatum. Bioresource Technol. 2007, 98, 3159-3163. 
11. Luo, A.X.; He, X.J.; Zhou, S.D.; Fan,Y.J.; He, T.; Chun, Z. In vitro antioxidant activities of a water-soluble polysaccharide derived from Dendrobium nobile Lindl. Extracts. Int. J. Biol. Macromol. 2009, 45, 359-363.

12. Wang, J.H.; Luo, J.P.; Zha, X.Q. Structural features of a pectic polysaccharide from the stems of Dendrobium nobile Lindl. Carbohyd. Polym. 2010, 81, 1-7.

13. Zha, X.Q.; Luo, J.P.; Luo, S.Z.; Jiang, S.T. Structure identification of a new immunostimulating polysaccharide from the stems of Dendrobium huoshanense. Carbohyd. Res. 2007, 69, 86-93.

14. Zhao, Y.P.; Son, Y.O.; Kim, S.S.; Jang, Y.S.; Lee, J.C. Antioxidant and Anti-hyperglycemic Activity of Polysaccharide Isolated from Dendrobium chrysotoxum Lindl. J. Biochem. Mol. Biol. 2007, 40, 670-677.

15. Fan, Y.J.; He, X.J.; Zhou, S.D.; Luo, A.X.; He, T.; Chun, Z. Composition analysis and antioxidant activity of polysaccharide from Dendrobium denneanum. Int. J. Biol. Macromol. 2009, 45, 169-173.

16. Luo, D.H. Identification of structure and antioxidant acti vity of a fraction of polysaccharide purified from Dioscorea nipponica Makino. Carbohyd. Polym. 2008, 71, 544-549.

17. Liu, Y.H.; Wang, F.S. Structural characterization of an active polysaccharide from Phellinus ribis. Carbohyd. Polym. 2007, 70, 386-392.

18. Zhao, M.M.; Yang, N.; Yang, B. Structural characterization of water-soluble olysaccharides from Opuntia monacanthap cladodes in relation to their anti-glycated activities. Food Chem. 2007, 105, 1480-1486.

19. Coimbra, M.A.; Goncalves, F.; Barros, A.S.; Delgadillo, I. FTIR spectroscopy and chemometric analysis of white wine polysaccharide extracts. J. Agr. Food Chem. 2002, 50, 3405-3411.

20. Barker, S.A.; Bourne, E.J.; Stacey, M.; Whiffen, D.H. Infrared spectra of carbohydrates. Part I. Some derivatives of D-glucopyranose. J. Chem. Soc. 1954, 171-176.

21. Maiti, D.; Chandra, K.; Mondal, S.; Ojha, A.K.; Das, D.; Roy, S.K.; Ghosh, K.; Chakraborty, I.; Islam, S.S. Isolation and characterization of a heteroglycan from the fruits of Astraeus hygrometricus. Carbohyd. Res. 2008, 343, 817-824.

22. Roy, S.K.; Maiti, D.; Mondal, S.; Das, D.; Islam, S.S. Structural analysis of a polysaccharide isolated from the aqueous extract of an edible mushroom, Pleurotus sajor-caju, cultivar Black Japan. Carbohyd. Res. 2008, 343, 1108-1113.

23. Cao, W.; Li, X.Q.; Liu, L.; Yang, T.H.; Li, C.; Fan, H.T.; Jia, M.; Lv, Z.G.; Mei, Q.B. Structure of an anti-tumor polysaccharide from Angelica sinensis (Oliv.) Diels. Carbohyd. Polym. 2006, 66, 149-159.

24. He, Y.M.; Liu, C.H.; Chen, Y.X.; Ji, A.C.; Shen, Z.L.; Xi, T.; Yao, Q.S. Isolation and Structural Characterization of a Novel Polysaccharide Prepared from Arca subcrenata Lischke. J. Biosci. Bioeng. 2007, 104, 111-116.

25. Yoon, S.; Kim, M.K.; Lee, I.Y.; Yun, M.; Nam Shin, J.E. Production and structural features of a water-soluble polysaccharide from a mutant strain of Agrobacterium sp. J. Ind. Eng. Chem. 2008, 14, 759-764.

26. Kath, F.; Kulicke, W.M. Mild enzymatic isolation of mannan and glucan from yeast Saccharomyces cerevisiae. Angew. Makromol. Chem. 1999, 268, 59-68. 
27. Wu, L.C.; Hsu, H.W.; Chen, Y.C.; Chiu, C.C.; Lin, Y.I.; Ho, J.A. Antioxidant and antiproliferative activities of red pitaya. Food Chem. 2006, 95, 319-327.

28. Oyanagui, Y. Reevaluation of assay methods and establishment of kit for superoxide dismutase activity. Anal. Biochem. 1984, 142, 290-301.

29. Asakawa, T.; Matsuhita, S. Colouring conditions of Thiobarbituric acid test for detecting lipid hydroperoxides. Lipids 1980, 15, 137-140.

30. Navarini, L.; Gilli, R.; Gombac, V. Polysaccharides from hot water extracts of roasted Coffea arabica beans: isolation and characterization. Carbohyd. Polym. 1999, 40, 71-81.

31. Xia, W.; Lv, Q.; Zhang, W.Q. Study on the Decoloration Of Polvsaccharides from M ulberry Leaves by M acro-resin Adsorption. Food Ferment. Ind. 2007, 33, 141-144.

32. Li, R.J.; Li, D.Y.; Zhang, X.F. Deproteinization from Epimedium Polysaccharide by Macroporous Adsorption Resin. Chem. J. Chin. Univ. 2006, 27, 67-70.

33. Dubois, M.; Gilles, K.A.; Hamilton, J.K.; Rebers, P.A.; Smith, F. Colorimetric method for determination of sugars and related substances. Anal. Chem. 1956, 28, 350-356.

34. Bradford, M.M. A rapid and sensitive method for the quantitation of microgram quantities of protein utilizing the principle of protein-dye binding. Anal. Biochem. 1976, 72, 248-254.

35. Yamamoto, Y.; Nunome, T.; Yamauchi, R.; Kato, K.; Sone, Y. Structure of an exocellular polysaccharide of Lactobacillus helveticus $\mathrm{TN}-4$, a spontaneous mutant strain of Lactobacillus helveticus TY1-2. Carbohyd. Res. 1995, 275, 319-332.

36. Pang, X.B.; Yao, W.B.; Yang, X.B.; Xie, C.; Liu, D.; Zhang, J.; Gao, X.D. Purification, characterization and biological activity on hepatocytes of a polysaccharide from Flammulina velutipes mycelium. Carbohyd. Res. 2007, 70, 291-297.

37. Luo, A.X.; He, X.J.; Zhou, S.D.; Fan, Y.J.; Luo, A.X.; Chun, Z. Purification, composition analysis and antioxidant activity of the polysaccharides from Dendrobium nobile Lindl. Carbohyd. Polym. 2010, 79, 1014-1019.

38. Shimada, K.; Fujikawa, K.; Yahara, K.; Nakamura, T. Antioxidative properties of xanthan on the autoxidation of soybean oil in cyclodextrin emulsion. J. Agr. Food Chem. 1992, 40, 945-948.

39. Smirnoff, N.; Cumbes, Q. Hyroxyl radical scavenging activity of compatible solutes. Phytochemistry 1989, 28, 1057-1060.

40. Re, R.; Pellegrini, N.; Proteggente, A.; Pannala, A.; Yang, M.; Rice-Evans, C. Antioxidant activity applying an improved ABTS radical cation decolorization assay. Free Radic. Biol. Med. 1999, 26, 1231-1237.

41. Lv, L.S.; Gu, X.H.; Tang, J.; Ho, C.T. Antioxidant activity of stilbene glycoside from Polygonum multiflorum Thunb in vivo. Food Chem. 2007, 104,1678-1681.

42. Wang, D.F.; Xie, X.F.; Cai, C.Y.; Yang, M. Analysis of pharmacological components of coarse tea curing diabetes. Chin. Trad. Herbal Drugs 1995, 26, 255-257.

43. Tsiapali, E.; Whaley, S.; Kalbfleisch, J.; Ensley, H.E.; Browder, I.W.; Williams, D.L. Glucans exhibit weak antioxidant activity, but stimulate macrophage free radical activity. Free Radic. Biol. Med. 2001, 30, 393-402.

44. Santanam, N.; Ramachandram, S.; Parthasarathy, S. Oxygen radicals, antioxidants, and lipid peroxidation. Semin. Reprod. Endocrinol. 1998, 16, 275-280. 
45. Dhalla, N.S.; Temsah, R.M.; Netticadam, T. Oxidative stress and cardiovascular diseases. J. Hypertens. 2000, 18, 655-663.

46. Sayre, L.M.; Smith, M.A.; Perry, G. Chemistry and biochemistry of oxidative stress in neurodegenerative disease. Curr. Med. Chem. 2001, 8, 721-738.

Sample Availability: Samples are available from the authors.

(C) 2011 by the authors; licensee MDPI, Basel, Switzerland. This article is an open access article distributed under the terms and conditions of the Creative Commons Attribution license (http://creativecommons.org/licenses/by/3.0/). 